\title{
The word frequency effect for recognition memory and the elevated-attention hypothesis
}

\author{
KENNETH J. MALMBERG \\ Indiana University, Bloomington, Indiana \\ and \\ THOMAS O. NELSON \\ University of Maryland, College Park, Maryland
}

\begin{abstract}
Empirical tests were conducted on the elevated-attention hypothesis that low-frequency (LF) words are better recognized than high-frequency (HF) words because LF words attract more attention than do HF words (e.g., Glanzer \& Adams, 1990). The elevated-attentionhypothesis predicts that the hit rate advantage for LF words should be reduced by increases in attentional strain at study. We first tested this prediction in two experiments by varying the amount of experimenter-controlled study time (on the basis of the assumption that a decrease in study time would reduce the amount of resources available for studying a word). The elevated-attentionhypothesis was confirmed, but only when words were studied for relatively short durations. This finding led us to formulate an early-phase elevatedattention hypothesis that proposes that more attentional resources are allocated to LF words than to HF words only during the early phase of encoding (which produces the LF hit rate advantage in subsequent recognition) and that the allocation of attentional resources during the late phase of encoding is not greater for $\mathrm{LF}$ words than for HF words. An additional empirical test of this revised hypothesis was conducted: Experimenter-controlled study time and the composition of the to-be-remembered pairs of words were varied orthogonally. The results confirmed the early-phase elevated-attention hypothesis.
\end{abstract}

The normative frequency of words is empirically related to performance of a variety of memory tasks, including recognition (Schulman, 1967; Shepard, 1967). Lowfrequency (LF) words are better recognized than highfrequency (HF) words, and the word frequency effect (WFE) is an example of a mirror effect (Glanzer \& Adams, 1985): For studied words, LF words are more likely than HF words to be recognized as being old (i.e., a hit), and for unstudied words, LF words are less likely than HF words to be recognized as old (i.e., a false alarm) ${ }^{1}$ We refer to these components of the WFE as the LF hit rate (HR) advantage and the $L F$ false alarm rate (FAR) advantage. In the following experiments, we investigated the effect of attentional strain on the LF HR advantage, and we tested a hypothesis for the allocation of attentional resources during learning.

In some theories, the allocation of attentional resources plays a critical role in producing the WFE. This account, referred to here as the elevated-attention hypothesis, is

This research was supported by NIMH NRSA Postdoctoral Fellowship MH12643 to K.J.M. and NIMH Grant K05-MH1075 to T.O.N. We thank William K. Estes and Eric-Jan Wagenmakers for informative discussions and Jeroen G. W. Raaijmakers for providing support while the first author was visiting the University of Amsterdam. Correspondence concerning this article should be addressed to K. J. Malmberg, Department of Psychology, Indiana University, Bloomington, IN 47405 (email: malmberg@indiana.edu) or T. O. Nelson, Department of Psychology, University of Maryland, College Park, MD 20742 (e-mail: tnelson@ glue.umd.edu). based on two premises: (1) LF words attract more attention than do HF words, and (2) the strength of an encoded episodic trace is a positive function of the amount of attentional resources allocated during encoding (e.g., Glanzer \& Adams, 1990; Maddox \& Estes, 1997; Mandler, 1980; Shepard, 1967). Other theories of recognition memory explain the WFE without invoking the elevated-attentionhypothesis (e.g., Shiffrin \& Steyvers, 1997), so a direct test of the elevated-attention hypothesis has important implications for one versus another theory of memory.

\section{Prior Findings}

The longevity and popularity of the elevated-attention hypothesis is somewhat surprising, because very little direct evidence supports it for recognition memory. Indeed, there is a considerable amount of disconfirming evidence.

A traditional way to operationalize amount of attention during study is via the amount of self-paced study time that the learner allocates to each item (e.g., Shaughnessy, Zimmerman, \& Underwood, 1972). The elevated-attention hypothesis predicts that LF words will be studied longer than HF words, a prediction confirmed by Rao and Proctor (1984, Experiment 2). However, in many experiments, the experimenter manipulates the presentation duration of the study trials. Thus, although measuring self-paced study time may provide convergent evidence, it does not provide a direct test of the elevated-attention hypothesis, because WFEs are observed even when subjects are allotted a fixed amount of time for a given study trial (e.g., $1 \mathrm{sec}$ ). 
In two studies (Hirshman \& Palij, 1992; Kim \& Glanzer, 1993, Experiments $2 a$ and $2 b$ ), the effects of experimenterpaced study time on subsequent recognition performance were investigated. On the assumption that limiting the amount of time a task is performed will limit the amount of resources allocated to the task (cf. Norman \& Bobrow, 1975), the elevated-attention hypothesis predicts that the LF HR advantage is positively related to study time (Hirshman \& Palij, 1992; Kim \& Glanzer, 1993).

Kim and Glanzer (1993, Experiments 2a and 2b) observed that increases in the amount of study time can yield a significant effect on performance and that the numerical magnitude of the LF HR advantage increased by approximately $4.5 \%$ when a forced choice involved an HF foil (Experiment 2a, .05 vs. .09; Experiment 2b, .04 vs. .09), but by only $1.5 \%$ when a forced choice involved an LF foil (Experiment $2 \mathrm{a}, .04$ vs. .06; Experiment 2b, .03 vs. .04). This finding suggests (1) that study time is positively related to the LF HR advantage or (2) that the frequency of the foil modulates the effect of attention during forced-choice recognition. However, using a similar study time manipulation, Hirshman and Palij (1992) found that the LF HR advantage in yes-no recognition was not affected by study time. Together, these findings provide mixed support for the elevated-attention hypothesis.

In the studies above, the effect of study time on the LF HR advantage was confounded with study-test delay. Therefore, the negative effects of increased delay may have traded off with the positive effects of increased study time. Study time had a significant effect on HRs and FARs in only one of the four experiments reported by Hirshman and Palij (1992), and although study time did significantly affect recognition performance in Kim and Glanzer's (1993) study, perhaps its effect on the LF HR advantage would have been more consistent had the study-test delay been controlled.

A completely randomized, within-list manipulation of study time can allow better control for lag. For example, Estes and Maddox (personal communication between William K. Estes and the first author, November 2000) found, using a ratings task, that the LF HR advantage is disrupted when single items are studied for short durations $(0.40$ vs. $1.2 \mathrm{sec})$.

However, two studies in which within-list manipulations of study time were used, conducted by Shiffrin and colleagues, provided mixed support for the elevatedattention hypothesis. Gillund and Shiffrin (1984, Figure 28), using a yes-no recognition task, observed that the frequency of the word with which a test item was studied had no effect on HRs. Clark and Shiffrin (1992, Experiment 1) required subjects to study three words at a time, and with a yes-no task, the critical finding was that when subjects received $2.5 \mathrm{sec}$ or less to study the triples, the LF HR advantage was slightly reversed. This finding could be explained if attentional resources were taxed to their limit when study time was relatively short and if LF words are typically allocated more resources than are HF words.

A single-item yes-no recognition experiment was used to test the elevated-attention hypothesis. If LF words at- tract more attention than do HF words, the magnitude of the LF HR advantage should increase as a positive function of study time. Therefore, HF and LF words were studied for either 0.25 or $2.5 \mathrm{sec}$ in a yes-no recognition task.

\section{EXPERIMENT 1}

\section{Method}

Subjects. Thirty undergraduates enrolled in introductory psychology courses at Indiana University participated in exchange for course credit.

Design and Materials. The $2 \times 2$ factorial design manipulated two within-subjects variables: normative word frequency (high vs. low) and study time (short vs. long). The primary dependent variable was HR. The word frequency of the foil test items was also manipulated (high vs. low), and the FAR was measured.

LF words occurred between 1 and 10 times per million, and HF words occurred more than 50 times per million (Kučera \& Francis, 1983). Words varied in length from four to eight letters. Each subject saw $96 \mathrm{HF}$ and $96 \mathrm{LF}$ words, and half of the HF words and half of the LF words were randomly assigned to be targets, with the remaining words being foils.

The list was constructed randomly anew for each subject, with the constraint that 48 words were HF words and 48 were LF words. Twenty-four words of each frequency were presented for $0.25 \mathrm{sec}$ of study, and 24 for $2.5 \mathrm{sec}$ of study. The interstimulus interval (ISI) was $150 \mathrm{msec}$. All of the studied words, along with the 96 interspersed words, were presented on a single-item yes-no recognition test, with the order of the items randomly determined anew for each subject.

Procedure. The subjects were instructed that they would be presented with a list of words to study and that their memory for the words would be tested after a brief math task. On each study trial, one word appeared on a computer screen. After study, a distractor task occurred, consisting of adding a series of single digits presented one at a time at a rate of one per $3 \mathrm{sec}$.

After the 30 -sec distractor task, a single word was presented in the center of the computer screen for a yes-no decision. Recognition was self-paced, and selecting either the "d" or the " $k$ " key on the computer keyboard entered the yes or the no response, respectively.

\section{Results}

Alpha $=.05$ is the standard of significance, the $t$ tests are two-tailed, and the $F$ values, unless otherwise noted, are from analyses of variance. Overall, a mirror-patterned WFE was observed. The FAR was significantly greater for HF than for LF words [.36 vs. .21 respectively; $t(29)=$ $5.61, S E M=0.03]$. For HRs, word frequency $[F(1,29)=$ $\left.5.89, M S_{\mathrm{e}}=0.02\right]$ and study time $\left[F(1,29)=34.72, M S_{\mathrm{e}}=\right.$ $0.01]$ had significant effects.

The elevated-attentionhypothesis predicts that decreasing study time should decrease the LF HR advantage. The interaction of word frequency and study time was significant $\left[F(1,29)=13.11, M S_{\mathrm{e}}=0.01\right]$. Figure 1 shows an LF HR advantage in the long study condition $[t(29)=$ 4.61, $S E=0.26]$, but not in the short study condition $[t(29)=0.18]$. The disruption in the LF HR advantage cannot be attributed to floor effects at the 0.25 -sec level of study time, because when the FAR (.29) is taken into account, the yes-no recognition performance was obviously above chance. Chance performance is indicated when HRs and FARs are approximately equal, but we find that FAR is approximately .26 less than the LF HR. These results confirm the prediction that the LF HR advantage 


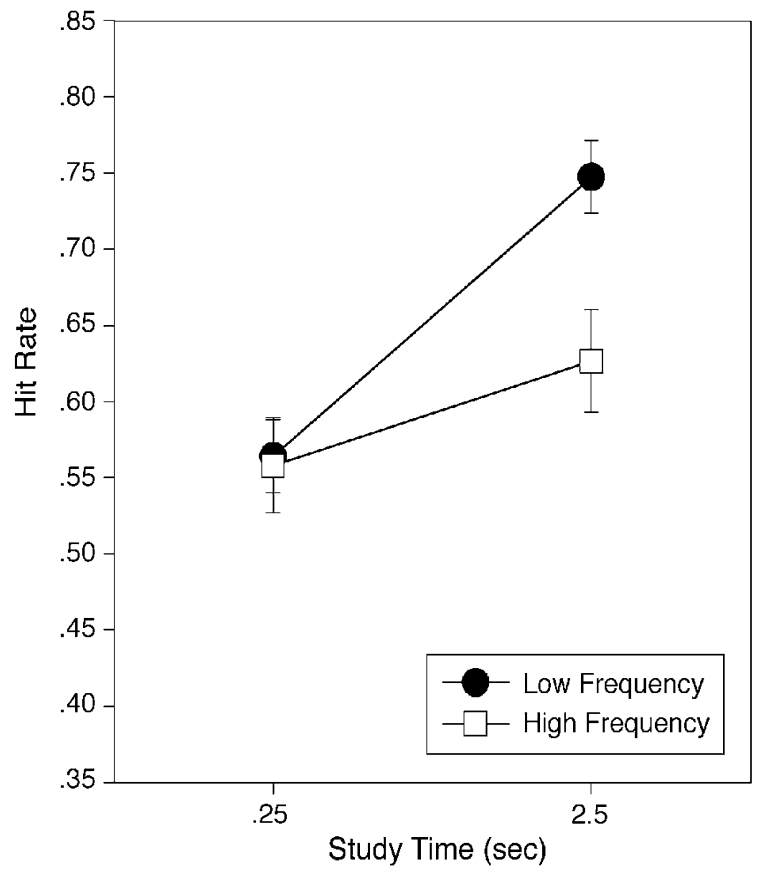

Figure 1. Hit rates as a function of word frequency and study time for Experiment 1. Error bars are standard errors.

would be disrupted when the amount of attentional resources devoted to studying words was limited via the study time manipulation, and they extend Estes and Maddox's finding to yes-no recognition.

\section{EXPERIMENT 2}

In Experiment 1, reducing study time decreased the LF HR advantage, a finding predicted by the elevated-attention hypothesis. In Experiment 2, we attempted to replicate this finding and extend it by manipulating study time over a wider range. We also included an intermediate level of study time so as to better observe the time course of the LF HR advantage. Therefore, all the subjects in this experiment studied words for $0.25,1.0$, or $3.0 \mathrm{sec}$

\section{Method}

Subjects. Forty-eight undergraduates enrolled in introductory psychology courses at Indiana University participated in exchange for course credit.

Design, Materials, and Procedure. The design, materials, and procedure were the same as those used in Experiment 1, with the following exceptions. For each subject, $120 \mathrm{HF}$ and $120 \mathrm{LF}$ words were randomly drawn from the appropriate partition of the word pool. The completely mixed study list consisted of 120 words $(60 \mathrm{HF}$ and 60 LF words). Twenty words of each frequency were presented for 0.25 , 1.0 , or $3.0 \mathrm{sec}$ of study. The ISI was $100 \mathrm{msec}$. The studied words and the 120 foils were individually tested, for a total of 240 singleitem yes-no recognition trials.

\section{Results and Discussion}

Overall, a mirror-patterned WFE was observed. The FAR was significantly greater for HF than for LF words
$[.37$ vs. .21 , respectively; $t(47)=9.10, S E M=0.02]$. HRs were significantly greater for LF words than HF words $\left[F(1,47)=21.07, M S_{\mathrm{e}}=0.03\right]$ and increased significantly with study time $\left[F(1,47)=54.80, M S_{\mathrm{e}}=0.01\right]$.

The interaction of word frequency and study time was significant $\left[F(1,47)=14.19, M S_{\mathrm{e}}=0.01\right]$ : Figure 2 shows a significant LF HR advantage in the 1.0- and 3.0-sec study conditions $[t(47)=4.70, S E=0.03$, and $t(47)=$ $4.69, S E=0.03$, respectively], but not in the $0.25-\mathrm{sec}$ study condition $[t(47)=1.14$, power $=.74]$. The interaction between word frequency and the 0.25 - and 1-sec study times $\left[F(1,47)=9.134, M S_{\mathrm{e}}=0.01\right]$ was significant, but it was nonsignificantbetween word frequency and the 1.0and 3.0-sec study times $[F(1,47)<1]$. Figure 2 shows that the LF HR advantage increased from 0.25 to $1.0 \mathrm{sec}$ of study but remained relatively constant thereafter. Figure 2 also shows that from 0.25 to $1.0 \mathrm{sec}$, study time had no effect on HF HR. This null effect is intriguing and may not be due to noise, insofar as the increase in study time from 0.25 to $1.0 \mathrm{sec}$ did increase the LF HR and inasmuch as Estes and Maddox (personal communication between William K. Estes and the first author, November 2000) found qualitatively identical results. The particular pattern of HRs showing an increase in the LF HR advantage from 0.25 to $1.0 \mathrm{sec}$ is surprising, and it probably should be investigated in the future. However, the extant results confirm the prediction of the elevated-attention hypothesis, albeit in a surprising manner. Moreover, the disruption in the LF HR advantage cannot be attributed to floor effects at the 0.25 -sec level of study time, because when the FAR (.21) is taken into account, the yes-no recognition performance was obviously above chance.

A strong version of the elevated-attention hypothesis predicts that the magnitude of the LF HR advantage will

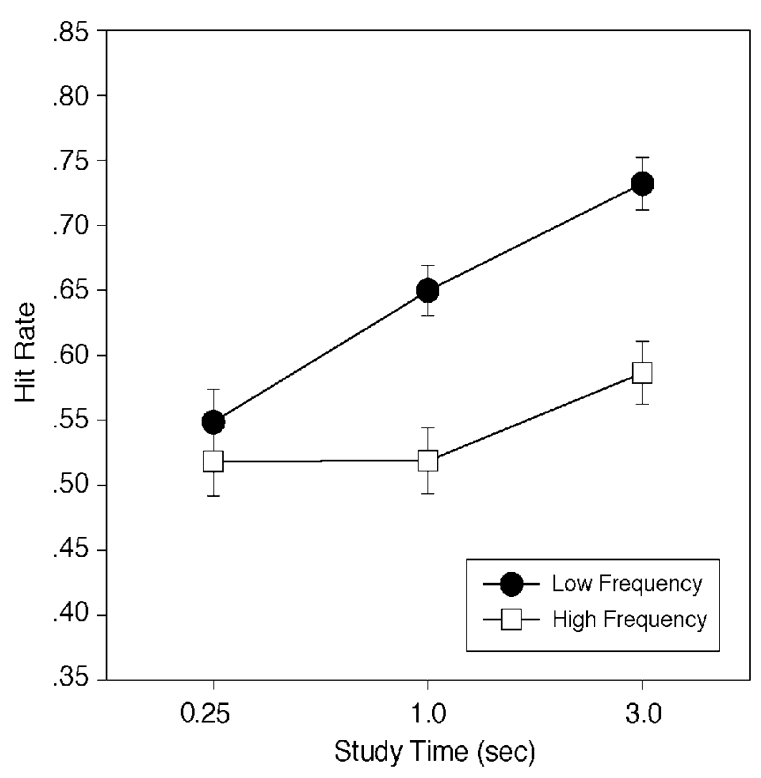

Figure 2. Hit rates as a function of word frequency and study time for Experiment 2. Error bars are standard errors. 
increase with study time. These findings disconfirm a strong version of the elevated-attention hypothesis, because the LF HR advantage increased with study time only when the study times were relatively short and did not increase when the study times were relatively long. To account for these findings, the elevated-attentionhypothesis is modified to state that there are two different phases of study: an early phase in which the allocation of attentional resources is greater for $\mathrm{LF}$ than for $\mathrm{HF}$ words and a late phase in which the allocation of attentional resources is not greater for LF than for HF words. We refer to this revised version as the early-phase elevated-attention hypothesis.

The early-phase elevated-attentionhypothesis proposes that an early phase of study provides initial processing of a word stimulus, which may be simple or configural, leading to the registration of a word's meaning in short-term memory. During this phase of study, the uncommon structural aspects of LF words make them more difficult to process than HF words (cf. Laberge \& Brown, 1989), and to overcome this disadvantage, more attentional resources are given for studying LF words than for studying HF words (see, also, Johnston \& Hawley, 1994). Devoting more resources to the encoding of words may also produce more complete, accurate, or so-called "stronger" memory traces. Thus, the mean HR is hypothesized to be greater for LF words than for HF words after the early phase of processing is completed.

HF words are identified about 100 msec more quickly than LF words (Besner \& McCann, 1987; Paap, McDonald, Schvaneveldt, \& Noel, 1987), and this difference in processing durations may contribute to the LF HR advantage. However, it alone may not be sufficient to explain all of the LF HR advantage. For instance, consider that foils are given $0 \mathrm{msec}$ of study and that the targets in the short study conditions of Experiments 1 and 2 were studied for $250 \mathrm{msec}$. Thus, the difference between the FAR and the HR in the short study condition reflects the amount of information stored in the first $250 \mathrm{msec}$ of study. For HF words, this difference is about .14, but for LF words, the difference is about .25. Thus, a significant amount of storage takes place in the first $250 \mathrm{msec}$ of study for both LF and HF words, with LF words benefiting to a greater degree than HF words. In addition, the LF advantage occurs prior to when words can typically be named (e.g., Besner \& McCann, 1987; Paap et al., 1987). Hence, it appears that a substantial amount of the LF HR advantage may be produced even before a difference in the amount of time to identify LF versus HF words can affect performance and, thus, additional time spent identifying LF words does not alone produce the LF HR advantage. ${ }^{2}$

If the additional time spent identifying LF words does not alone produce the LF HR advantage, then what else does? One factor that might also contribute to the LF HR advantage is the distinctiveness of the features being encoded in episodic memory during the early phase of study (e.g., Malmberg, Steyvers, Stephens, \& Shiffrin, 2002).

One way that feature distinctiveness may interact with the amount of storage to produce the LF HR advantage is if resources are limited for identifying a word and, initially, resources are exhaustively and evenly allocated to the processing of each structural feature of a word. If LF words are more difficult to process because they tend to have rather unusual features or configurations, resources initially devoted to the processing of relatively common features may be reallocated to unusual features that have not yet been fully decoded. The result of allocating more resources to processing unusual features is a relatively high probability of being encoded in long-term memory. The storage of an unusual feature would make its episodic trace relatively distinctive, and the longer processing durations would increase the number of features stored. When additional attentional resources are not devoted to analyzing a feature (e.g., HF features and/or when study time is sufficiently reduced), it might be less likely to be encoded. Thus, limiting the study time would limit the extent to which LF features may be allocated additional attentional resources and could disrupt the LF HR advantage.

We speculate that a later phase of encoding operations is responsible for the controlled processing of the item (Atkinson \& Shiffrin, 1968; Craik \& Lockhart, 1972; Nelson \& Narens, 1990), which may involve rote rehearsal, the creation of a mental image or sentence, or other metacognitive strategies for encoding the item in long-term memory. Perhaps, during the later phase of study, the amount of resources devoted to studying words is not greater for LF words than for HF words, and thus, the later phase of processing would not contribute to the LF HR advantage, which is supported by the findings that the LF HR advantage occurs very early during study and even when study time is experimenter paced (see above). This may have also been what Mandler (1980) had in mind when he wrote the following about the WFE:

Consider instructions to remember the words happy and frantic. It is likely that the response to the former would be to assume that one "knows that well" and needs to exert little effort to examine it, whereas the latter would receive at least some additional attention. Particularly when the exposure to the items is longer than a few seconds, such differential incrementing of the integration would not be expected. (p. 268)

Perhaps controlled processing typically utilizes generic knowledge retrieved from long-term memory to conceive of a word stimulus in such a manner as to encode an abstract representation of the mental situation in episodic memory (which may also include associative information). Thus, the information stored at this stage is typically abstract, and the fine-grained details of the event may be lost or misrepresented unless attended to. The abstract short-term representation of a word's meaning is based on the meaning of other words. For example, the words cello and bass differ in normative frequency, but both are likely to invoke thoughts of music, wood, strings, and so on, in which case these features are not likely to vary in distinctiveness as a function of normative word frequency, and controlled processing does not contribute to an LF HR ad- 
vantage. Lower level features may, under some circumstances, also be encoded at this time, but not without the application of attention to them (e.g., when a feature-level orienting task is performed).

\section{EXPERIMENT 3}

Experiment 3 was designed to test the hypothesis that LF words are given more attentional resources than are HF words early, but not late, during encoding. For this test, we used a design similar to the ones used by Gillund and Shiffrin (1984) and Clark and Shiffrin (1992), in which multiple items are studied concurrently. In our experiment, pairs of words were studied for either 1.2 or $4.0 \mathrm{sec}$, and the composition of the pairs was manipulated so that the pairs consisted of two HF words, two LF words, or one HF word and one LF word. The purpose of this study time manipulation was to vary the resources available for studying the word pairs (cf. Norman \& Bobrow, 1975). The purpose of the pair-type manipulation was to differentially tax attentional resources between pairs at a given level of study time (cf. Norman \& Bobrow, 1975). One reason for doing so is because the effect of longer study time on the LF HR advantage in Experiment 2 may have been scale dependent (cf. Townsend \& Ashby, 1984), and varying attentional load at different levels of study time allowed us to investigate this.

The proposal under investigation is that (1) the subjects typically attempt to decode both words (i.e., read or access their meanings) in a pair prior to processing either word in a controlled manner, (2) LF words require and are granted more attentional resources than HF words during the early phase of encoding, and (3) resources are not distributed preferentially to LF words during the late phase of encoding. This proposal predicts that words should be better recognized when they were studied with an HF word than when studied with an LF word in the short study condition, because more study time is spent accessing the meaning of LF words than that of HF words, but the frequency of the word with which a word is studied should not affect performance in the long study condition, because study time is sufficient for accessing the meanings of both words of a pair.

Also, the LF HR advantage may be harmed when LF words are studied with LF words, as compared with when HF words are studied with HF words in the short study condition, because the difference in attentional load is greatest for this comparison. By contrast, in the long study condition, this comparison should yield a significant LF HR advantage, because enough time should be available for the early stage of processing to be completed for all words.

\section{Method}

Subjects. Forty-three volunteers from introductory psychology classes at the University of Maryland at College Park participated in exchange for course credit.

Design and Materials. The design consisted of four withinsubjects variables: word frequency (high vs. low), study time (short vs. long), study orientation (top vs. bottom), and pair type (pure vs. mixed). LF words were defined as in Experiment 1. For each subject, $50 \%$ of randomly selected $96 \mathrm{HF}$ and $96 \mathrm{LF}$ words were assigned to be targets, and the remaining words served as foils.

The study list consisted of 48 pairs of words constructed randomly and anew for each subject, with the constraint that 16 were made up of two HF words, 16 of two LF words, and 16 of one HF and one LF word. Pairs of words were studied for either 1.2 or $4.0 \mathrm{sec}$, with one word appearing above the other in the center of a computer screen. The orientation of the HF and LF words for mixed pairs was determined randomly for each pair, with the constraint that $50 \%$ of the LF words were studied above an HF word for HF-LF pairs. Each of the studied words and the 96 foils were individually tested, for a total of 192 single-item yes-no recognition trials. Study and test order was randomly determined anew for each subject.

Procedure. The subjects were instructed that they would be presented with pairs of words to study and that, after a brief math task, their memory for the words would be tested. No specific orienting task was given. On each study trial, a point of fixation appeared in the center of a computer screen for $100 \mathrm{msec}$ and then was removed. Following directly thereafter, a pair of words was presented left justified to the point of fixation. One word appeared on the line above the point of fixation, and the other on the line below it. One hundred fifty milliseconds intervened between study trials. The math task involved adding a series of six single digits, presented one at a time at a rate of one per $5 \mathrm{sec}$. On each test trial, a single word was presented in the center of the computer screen, and the subjects were given $7 \mathrm{sec}$ to indicate yes or no by pressing one of two keys.

\section{Results and Discussion}

The effect of study orientation on the HRs was not significant $[F(1,42)=1.78]$ and did not interact with any other factor. Therefore, the remainder of the statistical analyses were conducted on the data collapsed over the study order variable. The mean HRs as a function of study time, word frequency, and the frequency of the word with which a word was studied (hereafter, called the companion word) are presented in Figure 3. The left and right panels of Figure 3 show the HRs for the short and the long study conditions, respectively, and the left and the right halves of each panel plot the HRs for words with HF companion words and LF companion words, respectively.

Overall, a mirror-patterned WFE was observed. The HRs for LF words were significantly greater than the HRs for HF words $\left[F(1,42)=19.53, M S_{\mathrm{e}}=0.24\right]$, and the FARs for LF words were significantly less than the FARs for $\mathrm{HF}$ words $[.21$ vs. .36 , respectively; $F(1,42)=44.85$, $\left.M S_{\mathrm{e}}=0.50\right]$.

The elevated-attention hypothesis predicts that a given word will be more likely to be recognized when it previously was studied along with an LF companion word than when it was studied with an HF companion word. The interaction of study time and the frequency of the companion word was significant $\left[F(1,42)=17.92, M S_{\mathrm{e}}=0.03\right]$. Comparing the left and the right panels in Figure 3 demonstrates this. The left panel of Figure 3 shows that in the short study condition, the mean HRs were significantly greater for words studied with an HF word than for words studied with an LF word $\left[F(1,42)=22.79, M S_{\mathrm{e}}=\right.$ $0.02]$. The interaction between the frequency of the target and frequency of the companion word was significant 


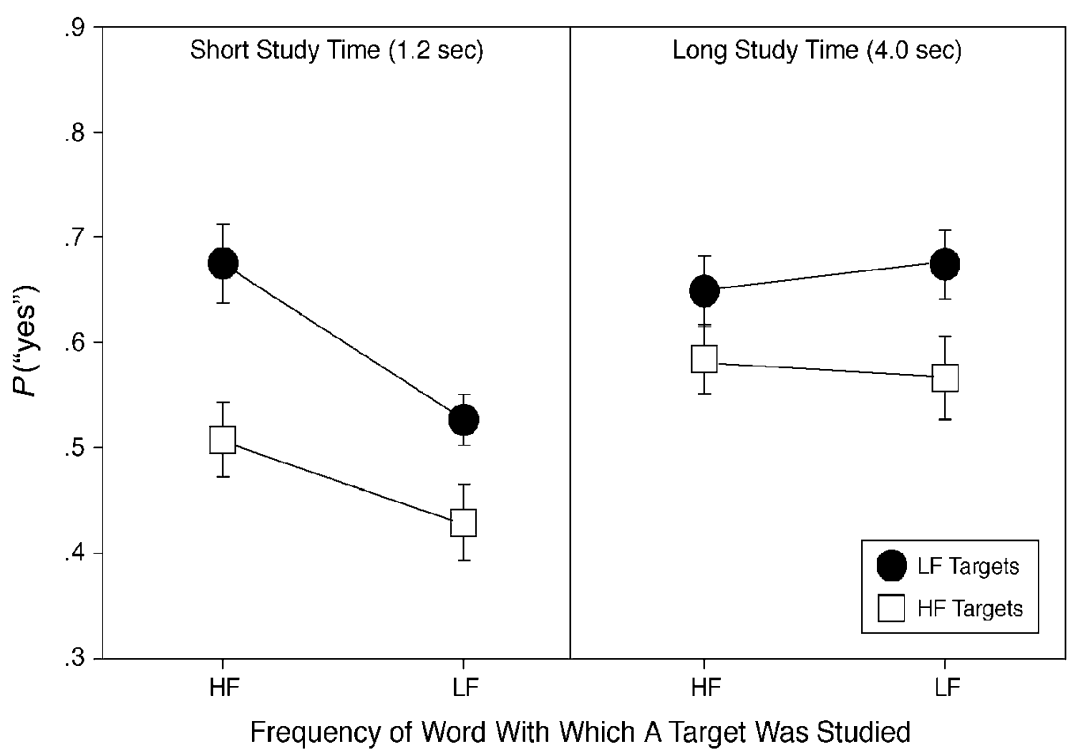

Figure 3. Hit rates as a function of word frequency, study time, and companion type for Experiment 3. Error bars are standard errors.

$\left[F(1,42)=22.91, M S_{\mathrm{e}}=0.02\right]$. This pattern of data is consistent with the hypothesis that more resources are devoted to studying LF words than HF words during an early phase of encoding.

In contrast, the right panel of Figure 3 shows that in the long study condition, the frequency of the companion word did not significantly affect the HRs $(F<1)$. The interaction between the frequency of the target and the frequency of the companion word was not significant $(F<1)$. This pattern of data is consistent with the hypothesis that more resources are not devoted to studying LF words than $\mathrm{HF}$ words during a later phase of encoding.

The early-phase elevated-attention hypothesis predicts that the LF HR advantage may be harmed in the short study condition when an LF word is studied with an LF word and an HF word is studied with an HF word, because the difference in the attentional load is greatest for these two conditions. The left panel of Figure 3 shows that for this comparison, the mean LF HR was not significantly different from the mean HF HR $[t(42)=0.35]$. In the long study condition, however, the mean LF HR was significantly greater than the mean HF HR $[t(42)=2.74, S E=$ $0.03]$. These findings are consistent with the hypothesis that once an early phase of processing is complete, the effect of attentional load on subsequent processing is not modulated by word frequency.

When the frequency of the companion word was controlled in the short study condition, the LF HR advantage was observed. That is, the mean HR was significantly greater for LF words than for HF words studied with an HF companion word $[t(42)=2.64, S E=0.04]$, and the mean HR was significantly greater for LF words than for HF words studied with an LF companion word $[t(42)=$ $3.60, S E=0.04]$. This finding confirms a prediction of the early-phase elevated-attention hypothesis that, early during study, the LF words will tend to attract more resources than than will the HF words.

The main finding from this experiment was that when pairs were studied for $1.2 \mathrm{sec}$, targets studied with LF companion words were less likely to be recognized than targets studied with HF companion words. However, when study time was increased to $4.0 \mathrm{sec}$, words studied with HF companion words were not better recognized than words studied with LF companion words, which is very similar to what Gillund and Shiffrin (1984) found. These findings are consistent with the early-phase elevatedattention hypothesis.

\section{GENERAL DISCUSSION}

These experiments tested the hypothesis that studied LF words attract more attention than do studied HF words. Experiments 1 and 2 employed a within-list manipulation of study time, which avoided the confound of variables present in some earlier studies (i.e., study-test lag vs. study time), and we found an increase in the LF HR advantage with an increase in study time. However, the results from Experiments 1 and 2 provided mixed support for the elevatedattention hypothesis, because study time and magnitude of the LF HR advantage were positively related only when study times were relatively short. Likewise, in Experiment 3 , attentional load affected the magnitude of the LF HR advantage, but only when study times were relatively short.

The hypothesis developed here to account for these findings proposes that studying a word involves two different sets of processes in which (1) during an initial phase of processing, an abstract representation of the word is encoded into short-term memory, and (2) during this phase, 
the LF words attract more attentional resources than do HF words. Thus, LF words tend to be more accurately or completely encoded in a long-term trace than are HF words. This early-phase elevated-attention hypothesis is indirectly supported by the findings that lexical decisions are faster for HF than for LF words (Besner \& McCann, 1987), that LF words take longer to read than HF words (Paap et al., 1987), and that naming and lexical decisions for LF words are undermined by increases in attentional load to a greater degree than are those for HF words (Herdman, 1992). In addition, Inhoff and Rayner (1986) have shown that LF words are gazed upon longer than HF words when read in a sentence, and Howes and Solomon (1951) found that the visual duration threshold is inversely related to normative word frequency.

Thus, there are several processes hypothesized to be involved in going from perceiving a word to becoming aware of its meaning that are sensitive to word frequency, including the processes involved in perceptual identification and lexical access. However, more than one process may contribute to more attentional resources being devoted to LF words than to HF words. Indeed, all of the aforementioned processes may be involved if, sometimes, the meaning of a word is not accessed on the first attempt. In such cases, multiple attempts might be made before success is achieved, and thus the characteristics of the word used to access its meaning may be more accurately encoded in an episodic trace.

Once the semantic characteristics of a word are accessible, control processes may begin to use this information to strategically encode the word in long-term memory. The amount of resources devoted to encoding the item into long-term memory is not influenced by its frequency, according to the present hypothesis. Thus, the LF HR advantage is explained by differences in the amount of resources devoted to initially processing a word, not by the amount of resources devoted to actively encoding the word into long-term memory. One finding that supports this assumption is that the HR for associative recognition is not greater for LF than for HF words (Hockley, 1994). If abstract associative information is used to probe memory to perform associative recognition and it does not consist primarily of lower level structural information of words, there should be no HR advantage for LF words.

Our findings are inconsistent with the proposition that LF words are better recognized than HF words because LF words borrow resources from HF words when studied. If LF words borrow rehearsal time from HF words studied on mixed lists, LF words should take away rehearsal from HF words when a pair of words is studied in both the long and the short study conditions. We found that when word pairs were studied for $4.0 \mathrm{sec}$, an LF HR advantage was observed, but the frequency of the word with which a target was studied did not affect recognition of the target. Therefore, we proposed that the amount of resources devoted to actively encoding the word into long-term memory is not typically responsible for the LF HR advantage. This is consistent with recent findings by Ward, Woodward,
Stevens, and Stinson (in press), who observed that HF words received more rehearsals than did LF words presented only for early serial positions (e.g., Rundus, 1971; Tan \& Ward, 2000). Moreover, our proposition is consistent with the findings of an LF HR advantage for both mixed-list and pure-list designs (e.g., Gorman, 1961; Schulman, 1967; Shepard, 1967) and for lists that vary in the percentage of HF versus LF words studied (Malmberg $\&$ Murnane, 2002).

Several experiments have been reported in which an orienting task appeared to disrupt the LF HR advantage. For example, Hirshman and Arndt (1997) and Hoshino (1991) instructed subjects to attend to the semantic properties of a word during study, and according to the earlyphase elevated-attention hypothesis, this might have created a situation in which the later phase of controlled processing allocated more resources to HF than to LF words (perhaps because they tend to be associated with more words in memory), thus disrupting the LF HR advantage. In addition, Hoshino instructed subjects to attend to the phonological properties of studied words, which may have caused the subjects to allocate more processing resources to the structural features of HF words (relative to a neutral orienting task condition) during the phase of controlled processing. Presumably, the structural properties of the LF words in Hoshino's study were stored during the early phase of processing, and therefore, the effect of the phonological orienting task was greater for HF than for LF words.

Joordens and Hockley (2000) observed a disruption in the LF HR advantage when subjects were required to make a speeded lexical decision at study. They interpreted this result within a dual-processing framework (cf. Atkinson \& Juola, 1974; Joordens \& Hockley, 2000; Reder et al., 2000; but see Malmberg, Zeelenberg, \& Shiffrin, in press) to mean that the lexical decision task negatively affected the subject's ability to recall the prior study events. In their experiment, however, the error rate was greater for $\mathrm{LF}$ than for HF words, and this is also consistent with the earlyphase elevated-attention prediction that the LF HR advantage will be disrupted when sufficient resources are not available during the early phase of word identification. The present findings are not necessarily in conflict with the dual-processing approach, but the early-phase elevated-attention hypothesis may help explain why LF words might be better recalled than HF words within that framework.

Our findings raise an interesting question: Are LF words allocated more resources early during study because they consist of more uncommon physical features than do HF words and/or does the storage of LF features create more distinctive episodic traces? That is, we proposed that LF words get encoded relatively accurately because more resources are devoted to processing the unusual orthographic, graphemic, and/or LF phonological features than are devoted to processing the relatively common features that tend to make up HF words. Alternatively, merely storing the unusual features may make LF 
traces more distinct than HF traces (e.g., Shiffrin \& Steyvers, 1997), thereby enhancing their recognition. If relatively distinctive features get stored only in the first second or so of study, the LF HR advantage should be produced very early during study and should not benefit from relatively long study times, which is consistent with our findings. It is not clear, however, how the alternative hypothesis would predict the finding that lexical decisions and perceptual identification are slower for LF words or would explain why gaze durations are longer when reading LF words, unless one assumes that the unusual LF features are also more difficult to process (i.e., require more time or attention), which is what we have proposed. Thus, these two explanations need not be mutually exclusive, nor do the present studies distinguish between these two accounts. It is sufficient to note that these two accounts are compatible and must be competitively examined in future research. Both accounts are in accord with the present data.

The present hypothesis is also related to one described by Johnston and Hawley (1994) and applied by Hintzman and Curran (1995) to explain the registration-withoutlearning phenomenon. Hintzman and Curran and Hintzman, Curran, and Oppy (1992) found that when an item is studied several times and then a frequency judgment is made to a new item that is perceptually very similar to the studied item, the unstudied item's judged frequency of occurrence increases with the number of repetitions of the studied item. That is, repetitions of the studied item are registered in memory. Interestingly, discrimination of the studied and similar unstudied words does not improve after approximately two repetitions of the target, which suggests that the features that discriminate between two similar items are not more likely to be learned as the result of further repetitions. We anticipate that further refinement will occur in future research that explores other ramifications of the early-phase elevated-attention hypothesis proposed here.

\section{REFERENCES}

AtKinson, R. C., \& Juola, J. F. (1974). Search and decision processes in recognition memory. In D. H. Krantz, R. C. Atkinson, R. D. Luce, \& P. Suppes (Eds.), Contemporary developments in mathematical psychology: Vol. 1. Learning, memory, and thinking (pp. 243-293). San Francisco: Freeman.

Atrinson, R. C., \& Shiffrin, R. M. (1968). Human memory: A proposed system and its control processes. In K. W. Spence \& J. T. Spence (Eds.), The psychology of learning and motivation (Vol. 2, pp. 89 195). New York: Academic Press.

Besner, D., \& McCann, R. S. (1987). Word frequency and pattern distortion in visual word identification and production: An examination of four classes of models. In M. Coltheart (Ed.), Attention and performance XII: The psychology of reading (pp. 201-219). Hillsdale, NJ: Erlbaum.

Clark, S. E., \& Shiffrin, R. M. (1992). Cuing effects and associative information in recognition memory. Memory \& Cognition, 20, 580-598.

Craik, F. I. M., \& LockharT, R. S. (1972). Levels of processing: A framework for memory research. Journal of Verbal Learning \& Verbal Behavior, 11, 671-684.

Gillund, G., \& Shiffrin, R. M. (1984). A retrieval model for both recognition and recall. Psychological Review, 91, 1-67.

GlanZER, M., \& ADAMS, J. K. (1985). The mirror effect in recognition memory. Memory \& Cognition, 3, 8-20.

GlanZer, M., \& ADAMS, J. K. (1990). The mirror effect in recognition memory: Data and theory. Journal of Experimental Psychology: Learning, Memory, \& Cognition, 16, 5-16.

Gorman, A. M. (1961). Recognition memory for nouns as a function of abstractness and frequency. Journal of Experimental Psychology, 61, 23-29.

Herdman, C. M. (1992). Attentional resource demands of visual word recognition in naming and lexical decisions. Journal of Experimental Psychology: Human Perception \& Performance, 18, 460-470.

Hintzman, D. L., \& CurRan, T. (1995). When encoding fails: Instructions, feedback, and registration without learning. Memory \& Cognition, 23, 213-226.

Hintzman, D. L., Curran, T., \& OpPY, B. (1992). Effects of similarity and repetition on memory: Registration without learning? Journal of Experimental Psychology: Learning, Memory, \& Cognition, 18, 667-680.

Hirshman, E., \& ARNDT, J. (1997). Discriminating alternative conceptions of false recognition: The cases of word concreteness and word frequency. Journal of Experimental Psychology: Learning, Memory, \& Cognition, 23, 1306-1323.

Hirshman, E. \& Palis, M. (1992). Rehearsal and the WFE in recognition memory. Journal of Memory \& Language, 31, 477-484.

HockLEY, W. E. (1994). Reflections of the mirror effect for item and associative recognition. Memory \& Cognition, 22, 713-722.

Hoshino, Y. (1991). A bias in favor of the positive response to highfrequency words in recognition memory. Memory \& Cognition, 19, 607-616.

Howes, D. H., \& Solomon, R. L. (1951). Visual duration threshold as a function of word probability. Journal of Experimental Psychology, 41, 401-410

InHoff, A. W., \& RAYNeR, K. (1986). Parafoveal word processing during eye fixations in reading: Effects of word frequency. Perception \& Psychophysics, 40, 431-439.

Johnston, W. A., \& Hawley, K. J. (1994). Perceptual inhibition of expected inputs: The key that opens closed minds. Psychonomic Bulletin \& Review, 1, 56-72.

Joordens, S., \& HockLey, W. E. (2000). Recollection and familiarity through the looking glass: When old does not mirror new. Journal of Experimental Psychology: Learning, Memory, and Cognition, 26, 15341555.

Kim, K., \& Glanzer, M. (1993). Speed versus accuracy instructions, study time, and the mirror effect. Journal of Experimental Psychology: Learning, Memory, and Cognition, 19, 638-652.

KuČera, H., \& Francis, W. (1983). Computationalanalysis of presentday American English. Providence, RI: Brown University Press.

LaBerge, D., \& Brown, V. (1989). Theory of attentional operations in shape identification. Psychological Review, 96, 101-124.

Maddox, W. T., \& Estes, W. K. (1997). Direct and indirect stimulusfrequency effects in recognition. Journal of Experimental Psychology: Learning, Memory, \& Cognition, 23, 539-559.

Malmberg, K. J., \& Murnane, K. (2002). List composition and the word-frequency effect for recognition memory. Journal of Experimental Psychology: Learning, Memory, \& Cognition, 28, 630-644.

Malmberg, K. J., Steyvers, M., Stephens, J. D., \& Shiffrin, R. M. (2002). Feature frequency effects in recognition memory. Memory \& Cognition, 30, 607-613.

Malmberg, K. J., Zeelenberg, R. \& Shiffrin, R. M. (in press). Modeling the effects of midazolam on the hippocampus and recognition memory. In S. Becker, S. Thrun, \& K. Obermeyer (Eds.), Advances in neural information processing systems 15.

MANDLER, G. (1980). Recognizing: The judgment of previous occurrence. Psychological Review, 87, 252-271.

Nelson, T. O., \& NARENS, L. (1990). Metamemory: A theoretical framework and new findings. In G. H. Bower (Ed.), The psychology of learning and motivation (Vol. 26, pp. 125-173). San Diego: Academic Press. Norman, D. A., \& Bobrow, D. G. (1975). On data-limited and resourcelimited processes. Cognitive Psychology, 7, 44-65.

PaAp, K. R., McDonald, J. E., Schvaneveldt, R. W., \& Noel, R. W. (1987). Frequency and pronounceability in visually presented naming and lexical decision tasks: Word frequency and pattern distortion in visual word identification. In M. Coltheart (Ed.), Attention and performance XII: The psychology of reading (pp. 221-243). Hillsdale, NJ: Erlbaum.

RaO, K. V., \& Proctor, R. W. (1984). Study-phase processing and the 
word frequency effect in recognition memory. Journal of Experimental Psychology: Learning, Memory, \& Cognition, 10, 386-394.

Reder, L. M., Nhouyvanisvong, A., Schunn, C. D., Ayers, M. S., Angstadt, P., \& HiRaki, K. (2000). A mechanistic account of the mirror effect for word frequency: A computational model of rememberknow judgments in a continuous recognition paradigm. Journal of Experimental Psychology: Learning, Memory, \& Cognition, 26, 294-320.

Rundus, D. (1971). Analysis of rehearsal processes in free recall. Journal of Experimental Psychology, 89, 63-77.

Schulman, A. I. (1967). Word length and rarity in recognition memory. Psychonomic Science, 9, 211-212.

Shaughnessy, J. J., Zimmerman, J., \& Underwood, B. J. (1972). Further evidence on the MP-DP effect in free-recall learning. Journal of Verbal Learning \& Verbal Behavior, 11, 1-12.

SHEPARD, R. N. (1967). Recognition memory for words, sentences, and pictures. Journal of Verbal Learning \& Verbal Behavior, 6, 156-163.

Shiffrin, R. M., \& STEyvers, M. (1997). A model for recognition memory: REM-retrieving effectively from memory. Psychonomic Bulletin \& Review, 4, 145-166.

TAN, L., \& WARD, G. (2000). A recency-based account of the primacy effect in free recall. Journal of Experimental Psychology: Learning, Memory, \& Cognition, 26, 1589-1625.

Townsend, J. T., \& Ashby, F. G. (1984). Measurement scales and statistics: The misconception misconceived. Psychological Bulletin, 96 , 394-401.
Ward, G., \& Woodward, G., Stevens, A., \& Stinson, C. (in press). Using overt rehearsals to explain the word frequency effect in free recall. Journal of Experimental Psychology: Learning, Memory, \& Cognition.

WiXTED, J. T. (1992). Subjective memorability and the mirror effect. Journal of Experimental Psychology: Learning, Memory, \& Cognition, 18, 681-690.

Zechmeister, E. B., Curt, C., \& Sebastian, J. A. (1978). Errors in a recognition memory task are a $U$-shaped function of word frequency. Bulletin of the Psychonomic Society, 11, 371-373.

\section{NOTES}

1. The exception is when very rare words are included in the manipulation (Wixted, 1992; Zechmeister, Curt, \& Sebastian, 1978).

2 . This analysis does not indicate whether the relationship between study time and the amount of storage is linear during the early phase of processing, but given the rather large differences in HRs and FARS, it does suggest that it is unlikely that the relationship between the amount of storage and the length of study is positively accelerating.

(Manuscript received January 21, 2002; revision accepted for publication September 19, 2002.) 